\title{
Farklılıkla Öğrenme Motor Becerilerin Öğrenimine Farklı Bir Bakış
}

\section{Güven ERDİL*}

\section{Öz}

Yetişkin ve çocuklar için kişiye özel ve yaratıcıllğa yönelik yeni yaklaşımlar gerçekleştirilmektedir. Bunu yaparken sıkıcı olmayan daha zengin, değişken ve uzun soluklu, tekrarlı olmayan antrenman programlarının hazırlanması gerekmektedir. Bu bağlamda bir tekniği öğrenme ve geliştirmenin daha kısa zamanda mümkün olması, hata oranının düşük ve doğru hareket uygulamalarının yapılması önemlidir. Bu yönteme göre klasik yöntemde öğrenilenlerden unutma oranlarının daha düşük olması olasıdır. Daha kalıcı performansa ulaşılmayı sağlayan ve durumlara daha hızlı tepki verebilme, ayrıca değişen ortam şartlarına karşı kişinin bilinçaltında hazır bulunması ve en erken zamanda uyum sağlamasını sağlayan motor becerilerin öğrenimi, son derece önem arz etmektedir.

Anahtar kelimeler: Motor öğrenme, beceri, farklılıkla öğrenme

\section{Differential Learning, A Different Wiev to the Learning of Motor Skils}

\begin{abstract}
New approaches for creativity and personalization are being realized for adults and children. While doing this, it is necessary to prepare more rich, variable and long-term, non-repetitive training programs that are not boring.

In this context, it is important to implement a low error rate and correct movement practices so that learning and developing a technique is possible in a shorter time. According to this method, it is possible that the forgetting rates are lower than those learned in the conventional method. Learning motor abilities that provide more lasting performance and faster response to situations, as well as the ability to be present at an unconscious level against changing ambient conditions and to adapt at the earliest time have the utmost importance.
\end{abstract}

Key words: Motor learning, skill, differential learning

* Prof. Dr. Guven.erdil@marmara.edu.tr, Marmara Üniversitesi Spor Bilimleri Fakültesi 
Merhabalar değerli spor dostlarım. Dergimizin bu sayısın da sizleri Türkiye’de çok yeni olan bir öğretim ve antrenman teorisi ile tanıştırmak istiyorum. 2013 yılında TFF deki Futbol Gelişim direktörlüğüm sırasında Almanya Mainz Üniversitesi’nden Prof.Dr.Wolfgang Schöllhorn ile başlatmış olduğumuz Farklılıkla Öğrenme yöntemini, Spor Federasyonlarımıza ve Kulüplerimize tanıtıp sporumuza farklı bakış açıları getirmek istiyoruz.

Günümüzde spor dallarında başarılı olabilmek için hataların minimize edilmesi gerekmektedir. Bazen milimetreler bazen de saliseler şampiyonlukları belirlemektedir. Artık bu yüzden yapılacak eğitimlerde hatalarında öğretilmesi gerekli hale gelmiştir. Prof.Dr. Schöllhorn Avrupa ve Asya' da hem kulüplerde hem de Federasyonlarda başarılı sonuçlar veren eğitim çalışmaları yaparak bu teorinin yaygınlaşmasını sağlamıştır. Amacımız en kısa zamanda bizim ülkemizde de çalışmaların başlatılmasıdır. Bu güne kadar uyguladığımız klasik öğretim yöntemine ek olarak Farklılıkla Öğrenme modelini uygulayarak ve yaygınlaştırarak sporcularımızın hatalara alışmasını sağlayarak en zor koşullarda bile başarılı olmalarını sağlamaktır. Önümüzdeki aylarda başlatacağımız ve antrenörlerimize yönelik olacak olan bu seminerler konusunda basında ve televizyonlarda detaylı bilgiler verilecektir.

Basit futbol oynamak en güzelidir ama basit futbol oynamak en zorudur.

\section{Johan Cruyff}

Doğru oynayabilmek için hiç bir zaman doğruyu öğrenme.

\section{Prof. Dr. Wolfgang Schöllhorn}

Birinin ayak izlerini takip ederek o kişi geçilemez.

François Truffaut (Fransız yönetmen)

\section{Klasik öğrenme}

Gösterilen hareketi devamlı tekrar ederek, mümkün olduğu kadar değişkenlik ve sapma göstermeden pekiştirmek.

- Kademeli, basamak basamak ilerleme

- Çok tekrar

- Hata düzeltmesi

- Değişen koşullarda hareketin öğrenildiği gibi uygulanabilmesi

\section{Futboldan Uygulama örneği}

Ayak içi topa vuruş

Topa doğru hafif yanal bir durumda ve düz bir doğrultu üzerinde hareket edilerek yaklaşılır.

- Destek ayağı vuruş yönünü gösterir.

- Vuruş eylemi ayak iç yüzeyi ile gerçekleştirilir. 
- Vuruş anında bilek eklem bölgesindeki gerginlik arttırılır ve dışa dönük yatay konum hale getirilir.

- Vuruş ayağının topa karşı yöneliminde yer ile topuk arası mesafe yaklaşık 6-7,5 cm olmalıdır.

- Topa hafif koşu ritmiyle düz olarak dik açıdan gelinir.

- Destek ayağı topun bir ayak genişliğinde mesafe ile topun yanına getirilir.

- Vuruş ayağı geriden getirilir ve kalçadan dışa doğru 90 derece çevrilir ve ayak içi hedefi gösterir.

- Vücut hafif öne doğru eğik olup, kollarm biri önde ve hafifçe dirsekten bükülür.

- Ayak topa vurduktan sonra vuruş ayağı salınıma devam eder ve vücut hafifçe geriye doğru bükülür.
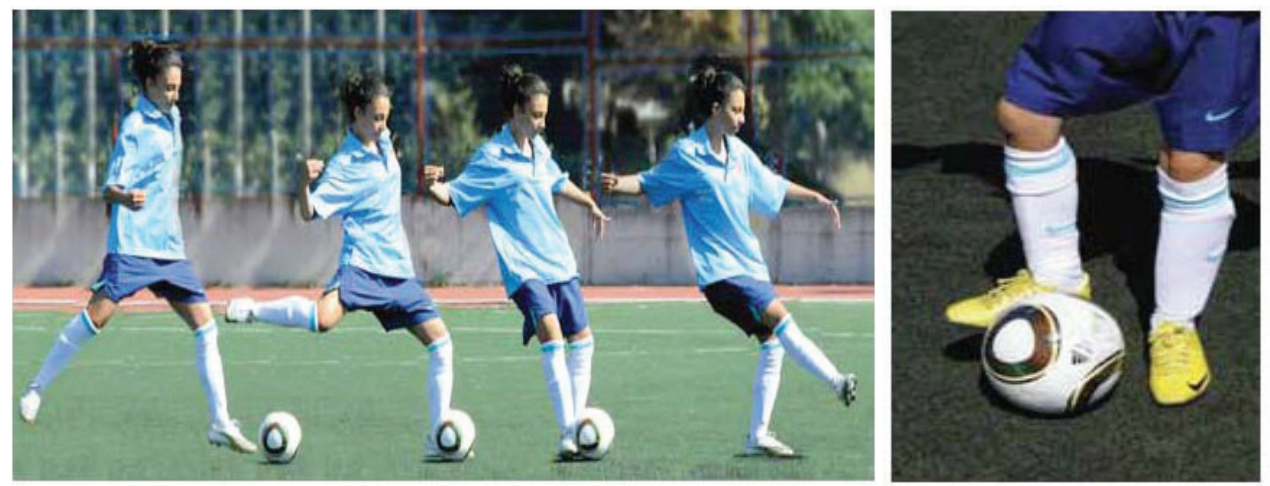

\section{Klasik öğrenme:}

Doğru teknik, kusursuz (kişinin özgün yapısından bağımsız) yüksek derecede değişmezlik, tutarlılık gösteren uygulamadır.

\section{Klasik öğrenmede sorunlar}

Ders kitaplarında belirlendiği gibi birbirine benzer ideal hareket akışının hedeflenmesi

\section{Hareketlerin aynı şekilde uygulanabilmesinin imkansızlı̆g göz önünde bulundurulmuyor.}

$\rightarrow$ Hareketler ne kadar birbirine benziyor olsa da çok sayıda sapmalar, aksaklıklar oluşmaktadır.

Örnek: Bir kişinin kendine özgü imzası ne kadar fark edilmeyecek kadar birbirine benzese de her attığı imza diğer imzadan farklıdır. (asıl öğrenme bu sapmalar ve aksaklıklarda saklı)

\section{Farklılıkla öğrenme yaklaşımı}

- Eğitmenlerin yapılan hatayı ikaz edip, düzeltmeyi benimsemesi sporcunun motorik alternatif çözümler bulmasını zorlaştırıyor.

- Sporcunun hata yapmasının önemi kalmıyor (makul çerçeve içinde). 


\section{Farklılıkla öğrenmenin tanımı}

Hareketlerin dalgalanmalarından yola çıkarak özörgütlü arayış ile tüm sapmalar ve aksaklıkları oluşturarak, kişiye özel en uygun çözüm yolunu bulabilmek

- Bilerek hedef odaklı uygulama çeşitliliği

$\rightarrow$ özörgütlü, kendinden organize olma

- Karşılaştırabilir

$\rightarrow$ iki farklı hal/durumdan üçüncü bir durumu tahmin etmek

- Hareket görevlerinin devamlı değişkenlik, çeşitlilik göstermesi

$\rightarrow$ Hedef: Oluşan yeni durumlara mümkün olduğu kadar çabuk ve uygun adapte olabilme (yüksek uyum sağlama özelliği)

- Birbiri ardına gelen hareket uygulamalarında devamlı farklılıklar yaratmaya vurgu yapma (feedback ile pekiştirme!)

$\rightarrow$ Hareketlerde ki zaten doğal olan dalgalanmaları (imza atma örneğinde olduğu gibi) hata olarak görmeyip hata düzeltmesi yapmaksızın daha da yükseltmek ve güçlendirmek

- Anlayış hareketlerin kontrolü, oluşan durumlara uyum sağlayan kasların eşgüdümlü hareket etmesinden kaynaklanıyor.

- Eşgüdüm ise iki bölüme ayrılır:

1. Vücut ve bölümleri kendi taslaklarına sahiptir.

2. Kişinin tercih ettiği hareketin taslağını MSS den seçerek beceriyi uygular.

3. Çalışma ve farkılıklar sayısındaki artış ile yeni taslaklar ortaya çıkar ve hareketin eşgüdüm taslağında gelişme olur.

4. Ne kadar çok taslak o kadar çok cevap verebilme kapasitesi Vücut hareketi, çevre nesneleri ve olayların taslağı ile ilişkilidir.

- Beceri uygulanacağı içerikle ilişkili olmalıdır.

- Hareket/motorik öğrenimi algılama ve deneyim çerçevesinde oluşturulmuş motorik taslaklarının arasından arayış ve deneyim sürecinden geçmek olarak görülüyor.

- Farklılıkla öğrenmenin fizyolojik boyutuBilginin büyük bir bölümü art arda gelen uyarıların farklılığında saklı olduğundan yola çıkarak motorik-sportif her tekrarlanan uygulamada bariz bir şekilde farklılıkların, sapmaların oluşturulması gerekiyor.

- Beyinsel-nörofizyolojik boyutta bu farklılıklar algılamayı uyarıp rutinden-sıradanlıktan çıkarıyor, yeni motorik programlar oluşturuyor.

- Böylece nöromotorik olarak oluşan ani sürpriz sapmalar ve aksaklıklarda dahi en uyumlu ve çabuk tepki verme becerisi zaman içinde geliştiriliyor.

- Duyusal (sensoriyel) sinir hücreleri ile motorik sinir hücrelerinin bağıntısından dolayı daha ince ayarlanabilir hareketler mümkün oluyor! 


\section{Duyu organlarının önemi}

- $\rightarrow$ DUYU ORGANLARININ algılamalarından ve uyarılarından bilginin sezilmesi (iç ve diş faktörlerin o an ki ortamda meydana gelen değişiminin uygun algılanması)

\section{Diş faktörler}

- Optik-göz

- Mekansal-zaman

- Akustik-kulak

- Dokunma hissi

İç faktörler

- Vestibüler

- Kinestetik

- Duyu organlarının önemi Kinestetik Sistem: Kinestetik sistemin reseptörleri kas tendonları ve eklemlerde bulunurlar. Bunlar ekstremitelerin konumu ve etki eden kuvvetler ve meydana gelen değişikliklere hakkında bilgi vermektedir (vücut ve kas dinamiği, uzama, gerilme, hızivmelenme, duruş, açı ve basinç).

- Proprioseptif algılama (derin duyum) dıștan değil içten, kendi bedeninden gelen sinyalleri oluşturur. Bu duyusal girdiler bilinç dışıdır ve merkezi sinir sistemine (MSS) karmaşık bilgiler olarak gönderilir ve MSS bu karmaşık bilgileri farklı farklı şekillendirir ve yerinde motorik hafıza oluşturur.

Bütün bu kontrol mekanizmaları birlikte çalışarak etkili, koordineli ve hassas hareketlerin yapılmasını sağlamak

$\rightarrow$ Kas-tendon duyu organları (Propiyoseptörler): Kas iğciği, pacini cismi, ruffini reseptör, golgitendon organı

$\rightarrow$ Hareketler, gereçler, zemin yapısı vs. açısından algılamak, his edebilme seviyesi

- Vestibüler Sistem: Başın hızlanması ve yönü hakkında bilgiler vermektedir. Bu denge organı ilişkili kas grupları ile bağlantılı. Afferent bağlantılı proprioseptif tepkileri destekleyici. Göz kasları ve beyin ile bağlantılı. Efferent olarak omurilik ve motor nöronlar ile bağlantılı uyarılara verilen cevapları perifere götürür.

- Doğrusal hızlandırma

- Rotasyon hizlandırma

- Denge durumu 
- Taktil Sistem (dokunma hissi): Algılayıcıları deriye yerleşmiştir ve bunlar o anki şekil ve yüzey hakkında bilgi vermektedir (cilt reseptörleri)

- Basınç (gereç, rakip oyuncu, ayak tabanı, eklemler)

- Hareketi etkileyen diğer hususlar (rüzgar)

$-\mathrm{H}_{12}$

- Hizlandirma

- Optik Sistem (görsel): Mesafeyi algılayan telereseptörler olarak tanımlanırlar ve bunlar özel, farklı ve yabancı hareketleri ve cisimleri haber verirler. Çoğu spor dallarında rakip oyuncu, çevresel durumları veya sporcunun ve spor gerecin hızını algılamak ve ona göre hareketlenmek görsel sistemin önemini göstermektedir. Merkezi görme ayrıntıları sezer, çevresel görme ise bedenin alanda ki konumunu ve hareketini hisseder.

- Görme ve algılama hızı

- Merkezi ve çevresel görüş

- Mekan/alansal ve zamansal çevre değişimi

- Vücudun alan ile ilişkisi

- Sportif gereç ile alanda seyri ile ilişkisi

- Oyuncu arkadaşların ve rakip oyuncuların davranışları ile ilişkili

- Sporcunun kendi hareketleri ile ilişkili

- Akustik Sistem (İşitsel): Genelde koordinasyon için dolaylı bir rol oynarlar. Yön bulmak için sinyaller algılar. Hareketleri destekleyen yardımlar (hılı ritim ve frekans duymak), hareket davranışı (örneğin 'ağır adım,'kayarak'), seyirci tutumu ve antrenör ve takım arkadaşından komutlar duymak.

\section{Tepki verebilme hızı!!!}

- M1 minosinaptik uzama-stretch refleksi (Kas iğciği, omurilik-kas, küçük gerilmeler) tepki hızı: 30-50 ms gecikme ile

- M2 işlevsel esneme-germe (uzun döngü) refleksi (Kas iğciği, omurilik-motor korteks-beyincikkas, Kas gücü-uzunluğu, eklem pozisyonu, düzeltmeye katkısı): 50-80 ms gecikme ile

- Tetiklenmiş reaksiyonlar (öğrenilebilmekte, otomatik tepki haline gelebilmekte): 80-120 ms gecikme ile

- İstemli reaksiyon zamanı tepkisi (çevresel etkilere duyarlı, tüm kasları etkiler, aynı pozisyonun sağlanmas1): 120-180 ms gecikme ile

- $\rightarrow$ Antrenmanlarda iç ve dış duyu sistemlerine (ama özellikle kinestetik duyu sistemine) devamlı farklılıklar içeren uyarılar göndermek. 


\section{Antrenman Örneği}

Farklılıkla öğrenme yöntemi için Futbol şut çalışması şeması

\section{Antrenman Örneği}

\section{Farklılıkla öğrenme yöntemi için Futbol şut çalışması şeması}

\begin{tabular}{|c|c|c|c|c|}
\hline $\begin{array}{l}\text { Gözün birini kapatarak } \\
\text { Gözünü açıp kapama } \\
\text { Hedefi önceden } \\
\text { belirleme } \\
\text { vs. }\end{array}$ & İlave Görev & & Topa gidiș & $\begin{array}{l}\text { Topuk çekerek } \\
\text { Yan adımlar atarak } \\
\text { Tek ayak üstünde } \\
\text { vs. }\end{array}$ \\
\hline $\begin{array}{l}\text { Kolun birini havada } \\
\text { tutma } \\
\text { Kolları çevirme } \\
\text { Vücudu bariz öne } \\
\text { getirme } \\
\text { vs. }\end{array}$ & Vücut Duruşu & Şut Çalışması & Destek ayağ 1 & $\begin{array}{l}\text { Destek ayağı topun çok önüne } \\
\text { Destek ayağı topun arkasına } \\
\text { Destek ayağını bükerek }\end{array}$ \\
\hline $\begin{array}{l}\text { Duran top } \\
\text { Dribling yaparak } \\
\text { Gelen topu kontrol } \\
\text { ederek } \\
\text { vs. }\end{array}$ & Oyun Pozisyonuna Göre & & Dominant ayak & $\begin{array}{l}\text { Hareketin hazırlık sayfasını } \\
\text { bariz bir şekilde arka-yana } \\
\text { yapmak } \\
\text { Dizi gergin tutmak } \\
\text { Doğal hareket akışını ani } \\
\text { frenlemek } \\
\text { vs. }\end{array}$ \\
\hline
\end{tabular}

(Hegen, Schöllhom 2012) 
Antrenman Uygulaması

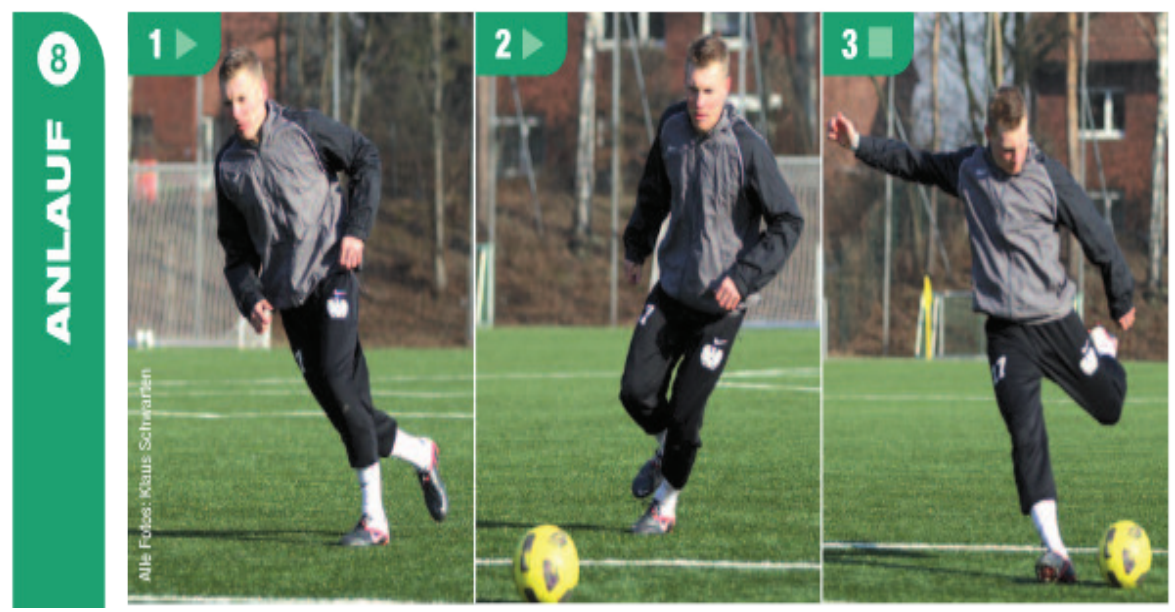

Koşu şekli odaklı

Topa gidiş (7 metreden zig zag yaparak topa gitmek)

Şut atışı (Serbest)

İlave görev (yok)

Direktif (kaleye şut)

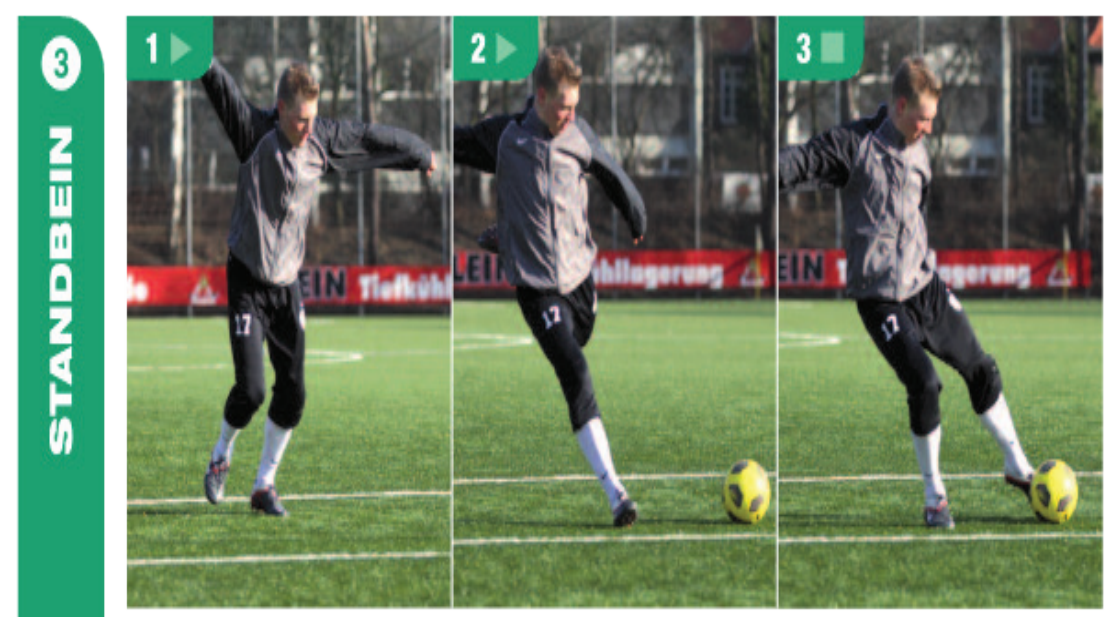

\section{Sabit ayak odaklı}

Topa gidiş (3 metreden topa normal gidiş)

Şut atışı (sabit ayağı toplam 20-30 cm uzaklıkta yanına koymak)

İlave görev (dominant ayağın dokunma alanı: ayak içi)

Direktif (sabit ayağını topun uzağına yanına koy ve kaleye şut at) (Hegen, Schöllhom 2012). 


\section{Antrenman Uygulamasi}

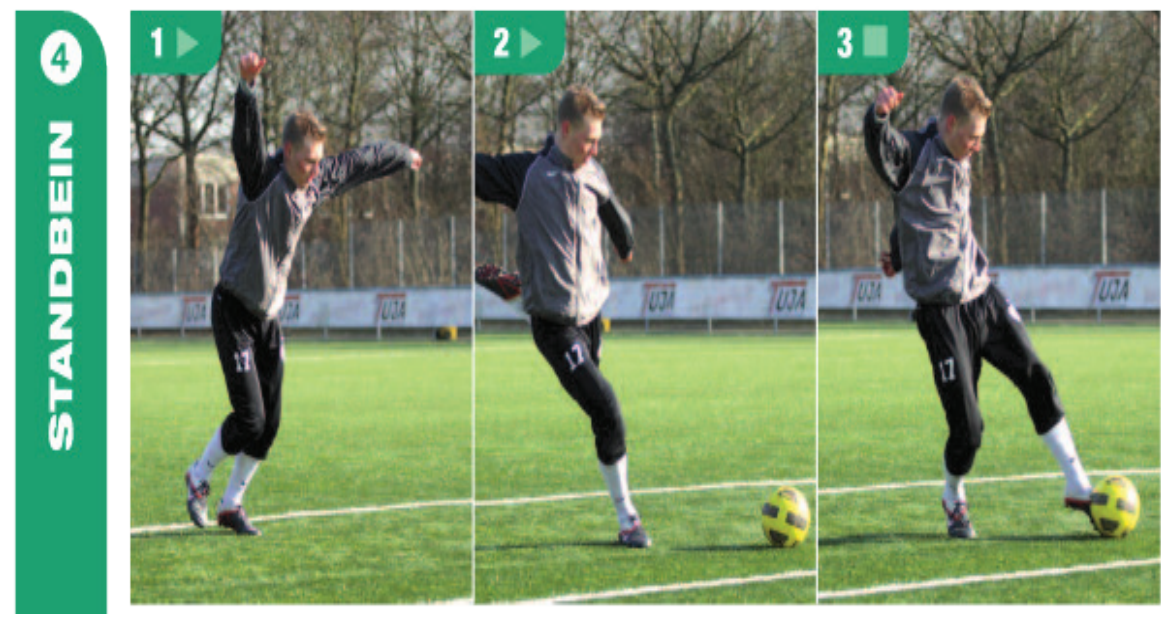

\section{Sabit ayak odaklı}

Topa gidiş (3 metreden topa normal gidiş)

Şut atışı (Sabit ayağı topun arkasına ve yana koymak)

İlave görev (Yok)

Direktif (Sabit ayağını topun uzağına arkasına koy ve kaleye şut at.)

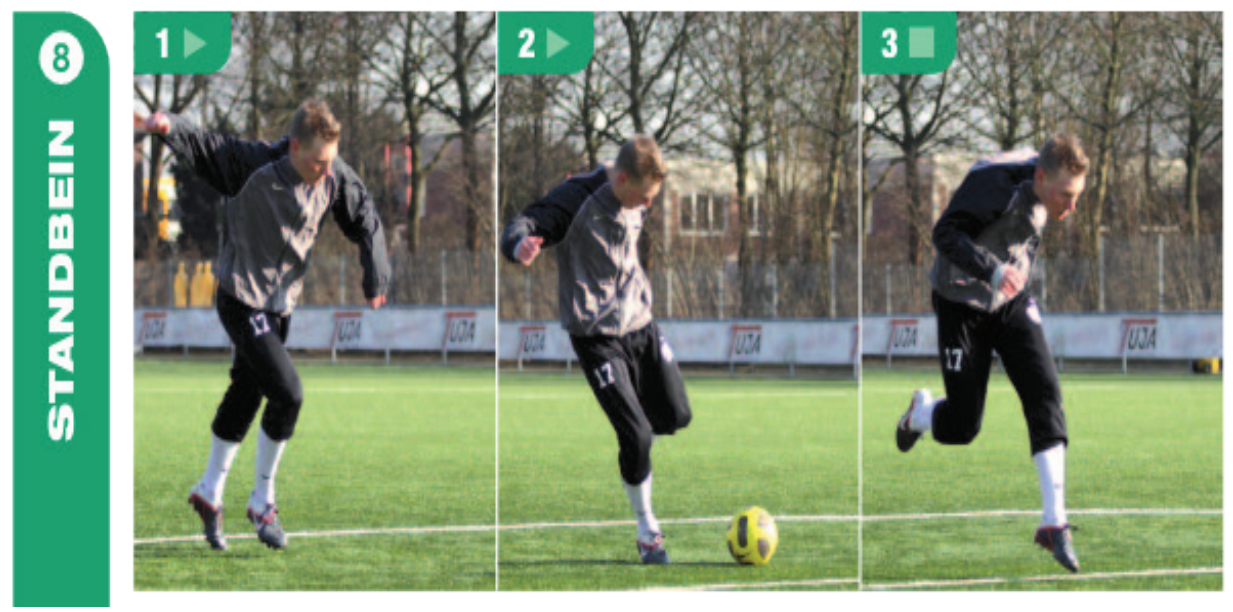

\section{Sabit ayak odaklı}

Topa gidiş (3 metreden topa normal gidiş)

Şut atışı (Sabit ayak ile sadece ayağın önü ile yere basmak)

İlave görev (3 farklı top ile şut atma)

Direktif (sabit ayağının sadece önü ile yere bas ve şuttan sonra ayağının üstünden öne koş) 
Antrenman Uygulaması

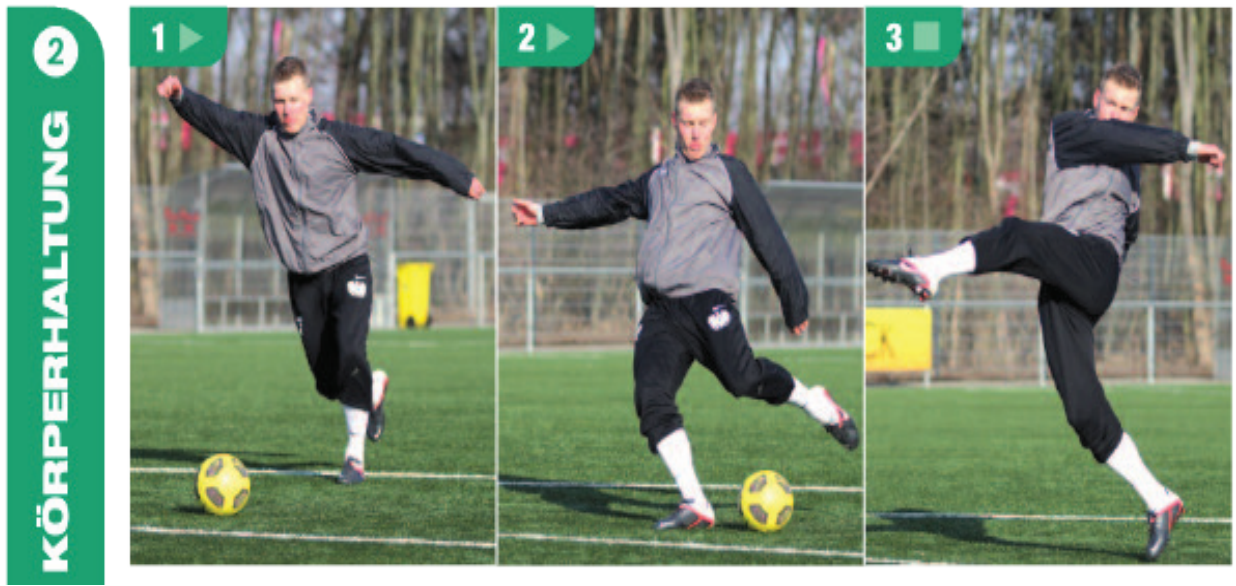

\section{Vücut duruşu odaklı}

Topa gidiş (5 metreden topa normal gidiş)

Şut atışı (Vücudu aşırı şekilde geriye yaslamak)

İlave görev (Şut yerden gitsin)

Direktif (Kaleye şutu yerden at ve vücudunu aşırı şekilde geriye yasla)

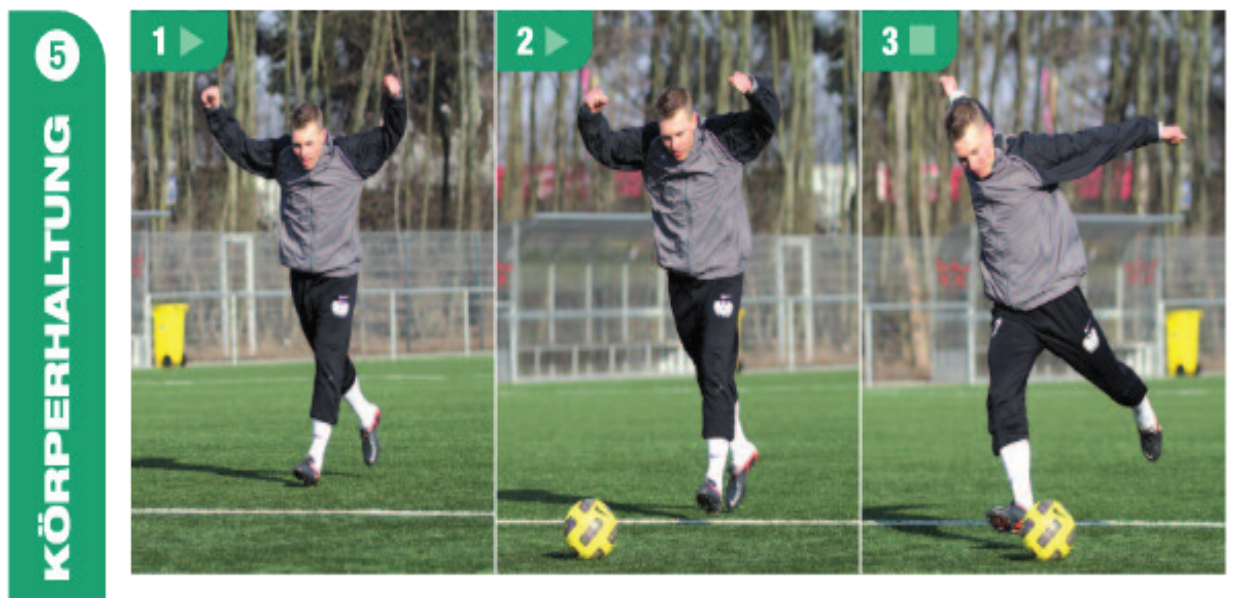

\section{Vücut duruş odaklı}

Topa gidiş ( 5 metreden topa normal gidiş ve kolları çevirmek)

Şut atışı (Serbest)

İlave görev (Yok)

Direktif (Koşarken kolları çevirerek kaleye şut at (kolları öne çevir/geriye çevir) 


\section{Antrenman Uygulamasi}

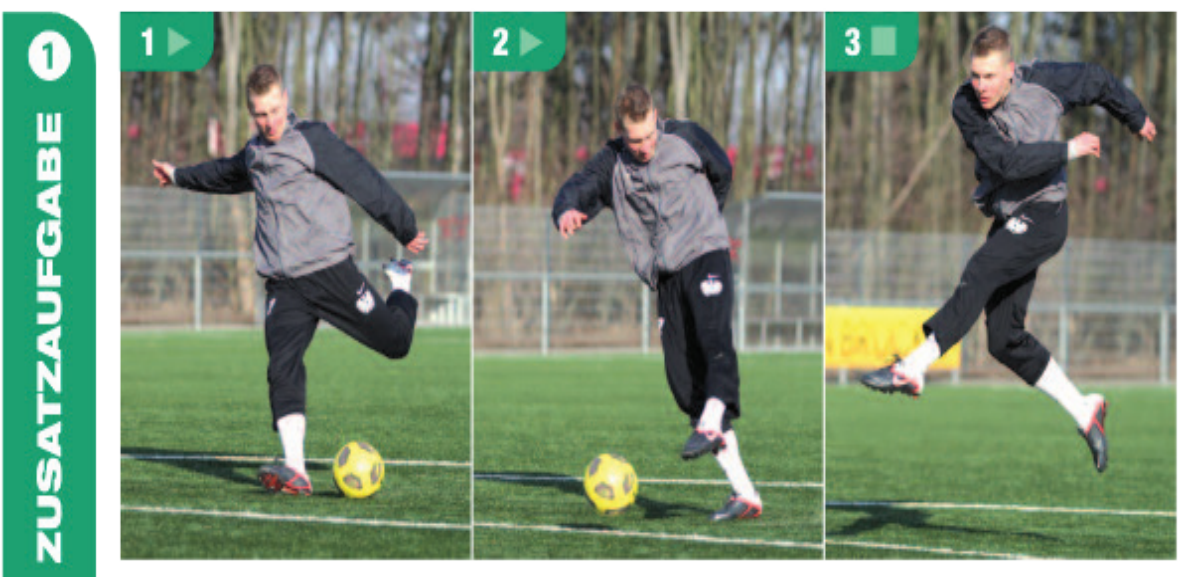

İlave görev odaklı

opa gidiş (5 metreden topa normal gidiş)

Şut atışı (Şutu attıktan sonra topun peşinden havaya atlamak)

İlave görev (Yok)

Direktif (Kaleye şut atar atmaz topun peşinden atla)
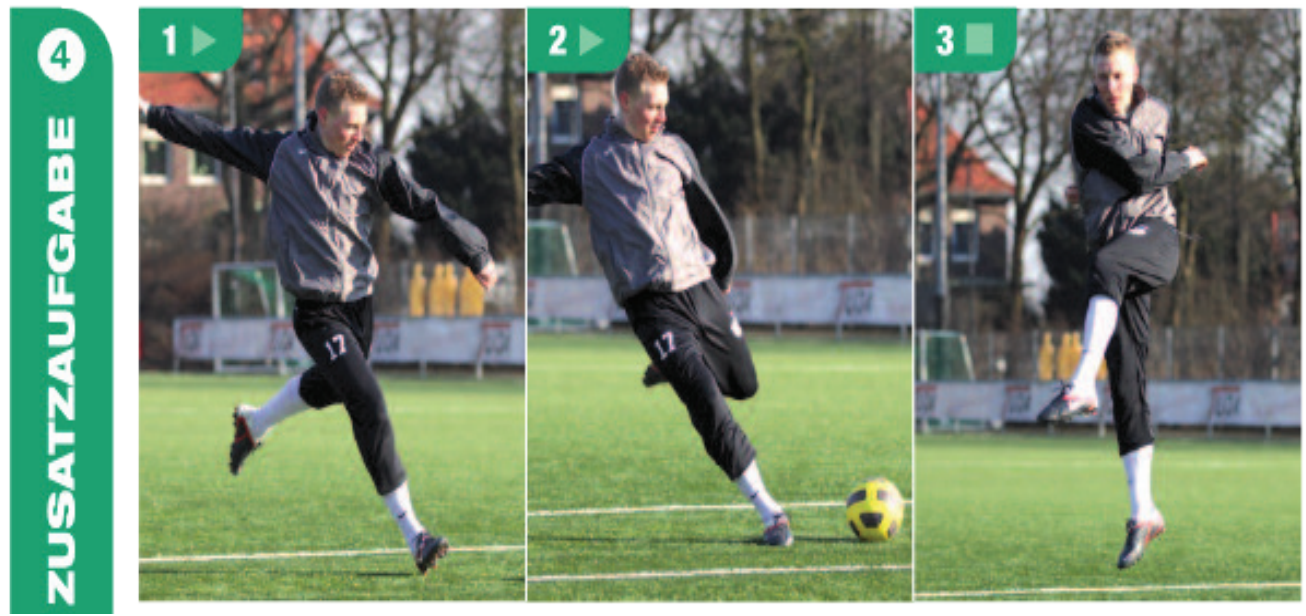

İlave görev odaklı

Topa gidiş (5 metreden topa normal gidiş)

Şut atışı (Şut atışından sonra dönerek havaya atlamak)

İlave görev (3'lü adımlarla 0 dan 15 e kadar saymak)

Direktif (Kaleye şut at ve arkasından yana dönerek atla) 


\section{KAYNAKLAR}

Çelebi, C.. Futbolda vuruş teknikleri: http://slideplayer.biz.tr/slide/1955797/

Erdil, G.. (2014). Nörofizyolojik Boyutuyla Sporda Bilateral Transfer, Akademi İstanbul

Beckmann, H., Schöllhorn, W. (2006). Differenzielles Lernen im Kugelstoßen; Leistungssport

Kasap, H., Bozkurt, S.: Sporda Beceri Öğrenimi Ders Notları

Wagner, H.U.A. (2004). Systemdynamische oder programmorientierte Lernmethoden; Leistungssport 34. Jahrgang; November.

Hegen P. Schöllhorn, W. (2012). Lernen an Unterschieden und nicht durch Wiederholungen.

Wastl, P. Anwendungsmöglichkeiten des Differenziellen Lernens im Sport. http://www.itps.uni-wuppertal. de/fileadmin/itps/Wastl/B-Abstract_08.pdf

Schmidt, R. A., Wrisberg, C. A., (2012). Çeviri Editörü: Ziya Koruç: Motor Öğrenme ve Performans, Anı Yayıncilık,Ankara

Kimmeskamp, S.. Differenzielles Lernen (DL) als eine Möglichkeit zur Individualisierung und Öffnung von Sportunterricht im Bereich der Technikschulung http://fssport.de/texte/SkriptDL.pdf

Schöllhorn U. A. W. (2004). Nie das Richtige trainieren, um richtig zu spielen; Leistungssport 34. Jahrgang; September.

Schöllhorn, W., Beckmann, H. Janssen, D. Michelbrink,M. (2009). Differenzielles Lehren und Lernen im Sport. Ein alternativer Ansatz für einen effektiven Schulsportunterricht. Sportunterricht. 